\title{
Forest management planning in the Terai: sharing experiences from Sabaiya, Parsa
}

\begin{abstract}
Y.B. Thapa, ${ }^{1}$ P.L. Shaha ${ }^{2}$, B. Ghimire ${ }^{3}$, Arjun K.C. ${ }^{4}$ and S. Karmacharya ${ }^{5}$
The Ministry of Forests and Soil Conservation is in the process of developing operational forest management mechanisms for the Terai regions of Nepal. The Sabaiya pilot scheme in Parsa is under implementation, which witnessed experiences in several issues in the process. The paper aims to share technical experiences with wider audiences. It highlights anomalies in scheme estimation and final enumeration in basic stand parameters such as basal area and volume. It presents possible reasons and provide analysis and insights for future management planning of Terai forests. The paper concludes with a need for more technical information generation, analysis and utilisation approaches in forest management in Nepal.
\end{abstract}

Key words: Forest management, stand parameters, volume table, Sabaiya

$\mathbf{T}$ he Ministry of Forests and Soil Conservation (MFSC) is in the process of developing operational forest management mechanisms for the Terai and inner Terai regions of Nepal. In the process, the MFSC tested with Woking Scheme, Operational Forest Management Plan (OFMP) approaches and recently put forward the concept of Collaborative Forest Management (CFM) through the Forestry Sector Policy 2000. The policy statement envisaged CFM for the Terai forests and states that contiguous large block of forests would be managed as CFM in collaboration with the local people and local governments. The programme has been in operation in Terai eight districts including the Parsa district with the support from the Netherlands government. However, immensity of the government-managed national forest is dominated by strict protection objectives, which need immediate active management (Acharya 2000). As a process to initiate active forest management, the Sabaiya pilot scheme is in operation for two years. The two years of implementation witnessed important experiences in technical issues on forest management planning. The paper aims to present implementation experiences and provide analysis and insights for future management planning of Terai forests.

\section{Pilot Sabaiya Scheme}

The Sabaiya pilot scheme was prepared in the fiscal year 2004/05 for the period of five years covering an area of 3,138.51 ha. The plan includes 15 Village Development Committees (VDCs) and Birgunj submetropolitan covering above 33,000 households totalling 197,011 populations. The technical proposal of the scheme proposes various harvesting operations such as regeneration felling, seeding felling and simple coppice management. Similarly, silvicultural activities include cleaning, weeding, regeneration protection and fire line management. The following section concentrates on implementation experiences in subcompartment $17 \mathrm{~B} 1$ prescribed for regeneration felling.

Table 1 : Total enumeration in $17 \mathrm{~B} 1$ and marked trees for felling

\begin{tabular}{lcccccc}
\hline \multicolumn{1}{c}{$\begin{array}{c}\text { Species economic } \\
\text { classification }\end{array}$} & $\mathbf{1 1 - 2 0}$ & $\mathbf{2 1 - 3 0}$ & $\mathbf{3 1 - 4 0}$ & $\mathbf{4 1 - 5 0}$ & $\mathbf{> 5 0}$ & \multirow{2}{*}{ Total } \\
\cline { 2 - 6 } Sal - Shorea robusta & 351 & 142 & $90(70)$ & $96(72)$ & $241(176)$ & $920(318)$ \\
Asna - Terminalia termentora & 2 & 9 & $29(18)$ & $28(26)$ & $32(25)$ & $100(69)$ \\
Satisal - Delbergia latifolia & 0 & 1 & 0 & 0 & 0 & $1(0)$ \\
Misc & 170 & 240 & $64(47)$ & $50(39)$ & $22(19)$ & $546(105)$ \\
Total & 523 & 392 & $183(135)$ & $174(137)$ & $295(220)$ & $1567(492)$ \\
Basal area marked for felling & N/A & N/A & 106.7 & 95.6 & 74.9 & \\
\hline
\end{tabular}

Figure in parentheses indicate number of trees marked for felling

\footnotetext{
${ }^{1}$ District Forest Officer, Parsa, Birgunj, Nepal

${ }^{2}$ Asst. Forest Officer, Parsa, Birgunj, Nepal

${ }^{3}$ Asst. Monitoring Officer, Parsa, Birgunj, Nepal

${ }^{4}$ Asst. Forest Officer, Regional Forest Directoriate, Hetauda, Nepal

${ }^{5}$ Communications Officer, BISEP-ST
} 
Table 2 : Projection vs final enumeration statistics of the sub-compartment (492 trees)

\begin{tabular}{lccccc}
\hline & $\begin{array}{c}\text { Basal area } \\
\left(\mathbf{m}^{2} / \mathbf{h a}\right)\end{array}$ & $\begin{array}{c}\text { Diameter } \\
\mathbf{( c m )}\end{array}$ & GS Volume & \multicolumn{2}{c}{ Total in 17 B1 $\left(\mathbf{m}^{3}\right)$} \\
\cline { 5 - 6 } & 20.0 & 45.0 & 194.0 & Firewood & Saw logs \\
\hline Scheme estimation & 13.7 & 32.7 & 86.9 & 1345 & 1184 \\
Final enumeration & 146 & 138 & 223 & $512 @$ & $577^{*}$ \\
Differences \% & & 1462 & 205 \\
\hline
\end{tabular}

Note: @One 20x5x5 chatta estimated to be $350 \mathrm{cu} \mathrm{ft}, * 1 \mathrm{~m}^{3}=27.73$ hoppus cu ft.

The area of the sub-compartment is 12.5 ha. The recommend prescriptions include removal of $5 \mathrm{D}$ (dead, dying, diseased, deformed, decaying/decayed) with priority with a total $50 \%$ basal area removal based on exploitable diameter (Anon., 2005). The exploitable diameter defined for sal forest type is more than $40 \mathrm{~cm}$ dbh and for rest of the forest types is more than $30 \mathrm{~cm} \mathrm{dbh}$. The basal area of $5 \mathrm{D}$ trees was $48.6 \mathrm{~m}^{2} / \mathrm{ha}$. The total number of trees was 1567 and marked number of trees for felling was 492 whereas actual felling was made for 133 trees. The existing security and other causes have prevented felling of all marked trees. The allowed harvestable basal area for $17 \mathrm{~B} 1$ was $109.8 \mathrm{~m}^{2}$. The total marked trees basal area in $17 \mathrm{~B} 1$ was $106.8 \mathrm{~m}^{2}$ with a safe margin of $3 \mathrm{~m}^{2}$ in the sub-compartment. The more elaborated enumeration is presented in Table 1.

\section{Scheme projection vs final estimation}

Table 2 shows the differences between scheme projection and final enumeration made prior to felling.

The table indicates systematic overestimated trends in all estimated parameters like basal area, average diameter and volume during the scheme preparation ranging from $138 \%$ to $262 \%$ compared to final enumeration. The higher percentages of differences indicate gap and anomalies in forest inventory process and volume estimation models. The volume estimation in scheme was based on Korhonen et al. (1994, cited in Anon, 2005) model for the western Terai whereas the volume estimation in the District Forest Office's enumeration was based on local volume table. The validity and applicability of the Korhonen model is not clear. On the other hand, the local volume table that District Forest Office uses lacks ownerships and identity. We were not able to describe who prepared this table, when and for which area- local or whole of the Terai as has been utilized in these days. In addition, the quality of the forest is significantly different that the time (must be more than 30 years) it was prepared. The more in-depth information will be generated after comparing actual volume harvested against projection in future.

Further analysis revealed that total volume estimation differs significantly on both fire wood and saw logs components. The information may indicate towards degraded quality of forests than was earlier projected or estimated based on diameter and height relationships. It means more trees are approaching to grade III classification (Government of Nepal timber grading system) in the area and saw logs are converted into firewood (photo 1). In addition, best trees are retained during regeneration felling allowing lower grade trees to be harvested. The graph 1 shows distribution of all enumerated trees in $17 \mathrm{~B} 1$ where more than half of trees are of grade III. The degraded quality of Terai forests is in consistent with earlier findings (Acharya, 2000; Sharma, and Suoheimo, 1995). The clear picture will emerge only after the availability of exact volume information from all harvested trees, which is not available presently.

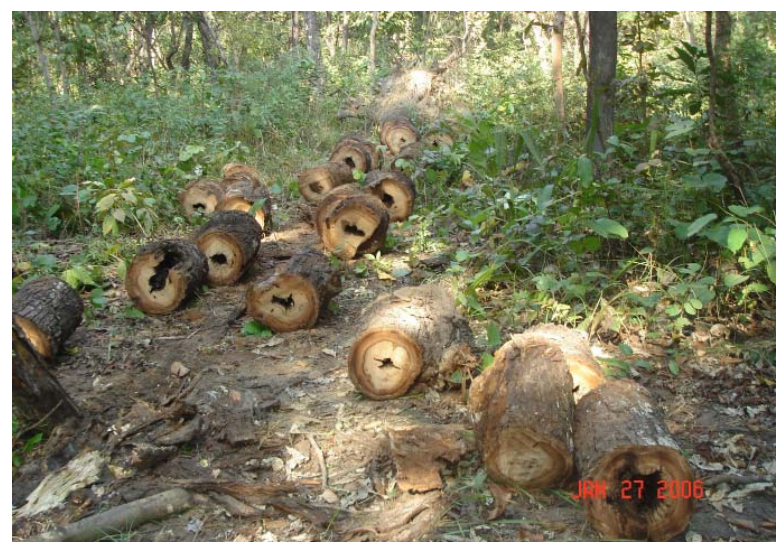

Photo 1 : Section of the trees indicating lower quality of remaining trees

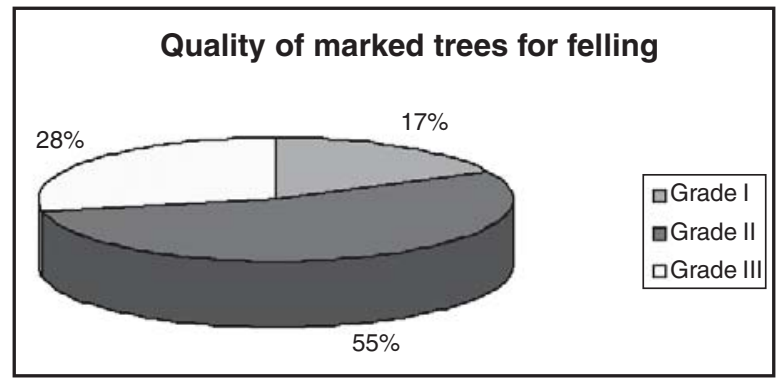

Figure 1 : Distribution of trees in different grade 


\section{Implication of differences}

The differences will have some serious concerns and implications for future planning. Firstly, it raises the issues, approaches and methodologies of data collection and validity of the information used for management planning purposes. The differences in enumeration and estimation would have impact on demand supply situation. In addition, differences in man days and revenue estimation would affect feasibility of the project. The lower yield against the estimation would rise needless questions on harvesting procedures and process due to variation in estimation. Finally, the planning, budgeting, and cost estimation procedures would be affected. The unambiguous information on costs, royalty and man days estimation will be accessible only after the harvest and sell of all estimated volume. However, it should be clear that data quality can only be improved through the collection, analysis and interpretation of further quality data in future.

\section{Hope for the future}

From technical perspectives, it was already demonstrated in small scale that active forest management in the Terai region is promising (Acharya and Acharya, 2004; Rautiainen, 1994). The regeneration after harvesting of old crop in Sabaiya is shown in the Photo 1. The Sabaiya implementation indicates a hope for active management of Terai forest. The subsequent monitoring of harvested plots and information would be useful in other areas specially balancing silviculture with socio-economic situation. Such activity will enhance capacity and build confidence of implementing agencies. The delay to initiate active management will reduce genetic stock, vigor and productivity.

\section{Conclusion}

There are significant differences in scheme estimation and enumeration on basic stand parameters. The causes are not always clear. The differences may be

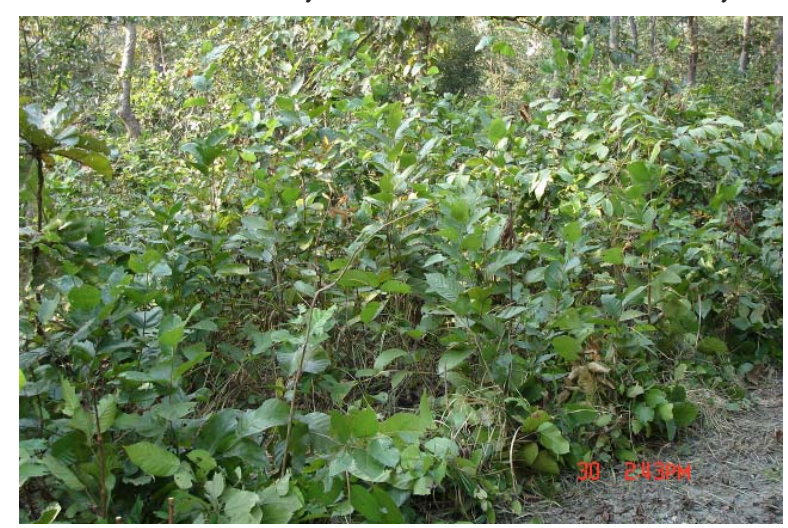

due to various data collection procedures and volume estimation models. The local volume table presently being used in the districts had serious questions of validity and applicability and the volume obtained in final harvesting is always less than the enumerated volume before felling. The differences in volume, revenues and man days will have implications on planning and budgeting, demand and supply projection and implementation process. The higher number of existing 5D trees indicates degrading forest stock requiring immediate active management. Attention is necessary to maintain $10 \%$ of $5 \mathrm{D}$ trees for biodiversity conservation as recommended in the scheme. It is necessary to update volume tables and management plans components based on further data and experiences. On the other hand, most of our Terai forest consists of mature and over mature trees with a little or negative growth of the existing growing stock in the forest. Moreover, the regeneration from a more stressed and degenerated crop could result in a stressed crop susceptible to diseases with reduced genetic behavior. However, the Sabaiya scheme implementation is expected to provide guidelines and information for future management planning. It also indicates for a remote hope for scientific management of remaining Terai forest. The basic elements required are strong political and bureaucratic commitment and favorable environment.

\section{References}

Acharya, K.P. and B. Acharya 2004. Early growth performance of natural Sal (Shorea robusta) forest in Central Nepal. Department of Forest Research and Survey, Forest Research Leaflet 17. Kathmandu, Nepal

Acharya, K.P. 2000. Unfavorable structure of forest in the Terai of Nepal needs immediate management, Banko Janakari 10(2):25-28.

Anon, 2005. Sabaiya Pilot Forest Management Scheme, CFMG/DFO Parsa.

Anon, 2000. Concept Paper for the Management of Terai and Inner Terai Forest of Nepal. The Ministry of Forest and Soil Conservation, Kathmandu, Nepal.

DFO 2006. Sabaiya Collaborative Forest Management Group: Total Enumeration- subcompartment 17 B1, document, District Forest Office (DFO), Parsa.

Rautianien, O. 1994. Natural Regeneration of Mixed Sal Forests. FMUDP Working Papers No 10. Forest Management and Utilisation Development Project/ National Forest Division, Kathmandu, Nepal.

Sharma, S and J. Suoheimo. 1995. Observation on rot in sal forests in the Terai, FMUDP working paper no 20, HMGN/FINNIDA, Kathmandu. 